\title{
Comparison of shipbuilding and construction industries from the product structure standpoint
}

\section{Conrad Boton*, Louis Rivest and Daniel Forgues}

Ecole de technologie superieure (ETS), 1100, rue Notre-Dame Ouest, Montréal, Québec, H3C 1K3, Canada

Email: conrad.boton@etsmtl.ca

Email: louis.rivest@etsmtl.ca

Email: daniel.forgues@etsmtl.ca

*Corresponding author

\author{
Julie R. Jupp \\ University of Technology Sydney, \\ 15 Broadway, Ultimo NSW 2007, Sydney, Australia \\ Email: Julie.Jupp@uts.edu.au
}

\begin{abstract}
The use of building information modelling (BIM) in construction compares to the use of product lifecycle management (PLM) in manufacturing. Previous research has shown that it is possible to improve BIM with the features and the best practices from the PLM approach. This article provides a comparison from the standpoint of the bill of materials (BOM) and product structures. It compares the product beginning of life in both construction and shipbuilding industries. The research then tries to understand the use, form and evolution of product structures and BOM concepts in shipbuilding with the aim of identifying equivalent notions in construction. Research findings demonstrate that similar concepts for structuring information exist in construction; however, the relationship between them is unclear. Further research is therefore required to detail the links identified by the authors and develop an equivalent central structuring backbone as found in PLM platforms.
\end{abstract}

Keywords: product lifecycle management; PLM; product structure; bill of materials; BOM; shipbuilding; construction; building information modelling; BIM; comparison

Reference to this paper should be made as follows: Boton, C., Rivest, L., Forgues, D. and Jupp, J.R. (2018) 'Comparison of shipbuilding and construction industries from the product structure standpoint', Int. J. Product Lifecycle Management, Vol. 11, No. 3, pp.191-220.

Biographical notes: Conrad Boton is a Professor in the Department of Construction Engineering of the École de technologie supérieure (Montréal, Canada). He holds a PhD in Architecture Sciences, a Master in Project Management and a Bachelor in Civil Engineering. Specialised in information technologies in construction and building information modelling (BIM), he has a significant professional and research experience in several national contexts. As part of his current research activities, he studies the organisational and technological issues related to the implementation of BIM in Canadian architecture, engineering and construction firms. 
Louis Rivest became a Professor at the École de technologie supérieure in Montréal, Canada, after spending a few years in the aerospace industry. He has obtained his PhD from the École Polytechnique de Montreal in 1993 and his Bachelor in Mechanical Engineering in 1988. His research centres on the models, methods, tools and processes supporting complex and multidisciplinary product development. His teaching and research activities relate to CAD, product data management, PLM and Industrie 4.0.

Daniel Forgues is a Professor in the Department of Construction Engineering of the École de technologie supérieure (Montréal, Canada), with 25 years of experience in managing projects and programs for various sectors including real estate, IT and manufacturing. He is a co-Founder of the Research Group on Integration and Sustainable Development (GRIDD). He also holds the Pomerleau Industrial Chair and heads a research laboratory on integrated design and building information modelling (BIM).

Julie R. Jupp is an Associate Professor in the School of the Built Environment at the University of Technology Sydney. Her research focuses on digital design and construction and the application of innovation in the context of large construction projects, encompassing building information modelling (BIM), product lifecycle management (PLM) and multidisciplinary design optimisation. Her main interests lie in improving information flow in the construction industry and managing information beyond the project lifecycle.

This paper is a revised and expanded version of a paper entitled 'Comparing PLM and BIM from the product structure standpoint' presented at IFIP WG 5.1 International Conference, PLM 2016, Columbia, SC, USA, 10-13 July 2016.

\section{Introduction}

Considered to be refractory to information technology (Howard et al., 1989), the construction industry has suffered a great delay in terms of productivity compared to other industries such as aerospace and automotive (Egan, 1998). The industry is characterised by high fragmentation, heterogeneous project teams and a lack of interoperability. For decades, several studies have explored the role of information technology as an integrating element and enabler of productivity without much success until recently (Arayici et al., 2011; Howard et al., 1989; Sacks and Barak, 2008).

Yet, with the rise of building information modelling (BIM) (Eastman et al., 2008) or BIM, the industry seems at a crossroads. Indeed, BIM appears to have the potential to solve a number of persistent problems in the sector (interoperability, optimisation of information flows, etc.) that will lead to improvements in productivity (Eadie et al., 2013; Sacks and Barak, 2008). While early studies focused on interoperability issues and other technological improvements, it appeared quite soon that the great value of BIM lay in collaboration and optimisation of information flows throughout the project lifecycle (Eadie et al., 2013), which is deemed as the source for most of the current limitations of the BIM approach.

BIM uses a multidisciplinary object-oriented three-dimensional (3D) model of the buildings in order to improve and to document its design and to simulate different aspects of its design performance, its construction or its operation (Eastman et al., 2008). Smith and Tardif (2009) define BIM as a systems approach to the design, construction, 
ownership, management, operation, maintenance, use and demolition or reuse of buildings.

PLM or product lifecycle management, on the other hand, is defined by Terzi et al. (2010) as

“...a business strategy for creating and sustaining [...] a product-centric knowledge environment. It is rooted not only in design tools and data warehouse systems, but also on product maintenance, repair and dismissal support systems. A PLM environment enables collaboration between - and informed decision making by - various stakeholders of a product over its lifecycle."

Hence, both BIM and PLM are similar in terms of key concepts: they are approaches based on information tools and models, in order to enable collaboration throughout the 'product' lifecycle. They differ, however, by focusing on distinct domains: BIM is typically applied in building design and construction while PLM is typically used in product design and manufacturing, such as cars, aircrafts or shipbuilding industries. They also differ in relation to the tools, workflows and standards that are used to implement each approach. Comparing BIM and PLM is therefore a useful endeavour that could help improve both domains through cross-pollination.

Recent research (Aram and Eastman, 2013; Jupp, 2013, 2016; Jupp and Nepal, 2014) has been dedicated to improving BIM based on best practices from PLM in other discrete manufacturing industries. Note that the notion of 'discrete manufacturing' refers to "the production of discrete items (e.g., cars, aircraft and appliances)" (Pinquié et al., 2015). It then categorises "terms such as aeronautics, boat, marine, apparel, fashion industry, automotive, washing machines, heavy machinery industries, luxury industry, naval engineering" (Pinquié et al., 2015). Jupp (2016) recently studied the consequences of incomplete BIM implementation in construction projects. The results suggest that the PLM approach actually provides interesting features to solve many of the problems currently encountered in the BIM approach. Indeed, similarities exist between the current upheavals in construction and the changes observed in complex manufacturing industries a few years ago with the arrival of the PLM approach (Jupp and Nepal, 2014). In addition, the philosophy and overall objectives of BIM are similar to those of PLM. Holzer (2014) suggests that, instead of evolving into a construction-dedicated PLM approach, BIM should be developed in such a way that it is possible to directly stem the structured product data from the model to the existing information systems across the industry. Thus, he presents the bill-of-materials (BOM) as the missing link between BIM and existing (and largely disconnected), feasibility, design, construction and operational processes (Holzer, 2014). While the concept of the BOM is widely used in many industrial sectors, the product structure (PS) is central to PLM systems. Both concepts are similar but not identical. However, these two concepts are useful and practical in manufacturing industries to convey information throughout the entire lifecycle of a project. We could reasonably argue that PLM systems would not be the same without a PS and a BOM to organise and exchange data.

Since the construction industry is comparable to some other discrete manufacturing industries, despite some notable differences, these concepts then appear to be very interesting directions with good potential in enabling an information-centric management approach to design and construction enabled by BIM. Opportunities in the construction industry for advances in the way product and product-related data is structured and 
referenced have the potential to provide the type of standard contextual foundations found in PLM domains. It is the objective of such foundations to link product ecosystems and support integration so as to minimise the need for manual, time-consuming, error prone, point-mapping between information systems and lifecycle phases.

This article is part of a more comprehensive study with the objective of comparing BIM and PLM approaches from different perspectives. It focuses on two similar industries (shipbuilding and construction) and explores the use and the evolution of BOM and PS in the beginning of life (BOL) of a ship. It then tries to identify the corresponding concepts in the BOL of a building. The aim is to be able to establish a comparison between BIM and PLM based on a factual approach.

\section{Related works and research approach}

\subsection{Related works}

While manufacturing industries have been able to customise and tailor parametric tools, relying on long-term working relationships, such practices seem not practical in the architecture, engineering, construction and operation (AECO) industry which, unlike other industries such as aerospace and automobile, "relies on open partnering of small businesses $[\ldots]$ on projects that commonly extend for periods of three years or less" (Eastman et al., 2010).

Some notable previous research works have been dedicated to the study of BIM in the light of PLM practices. Based on an empirical research, Jupp (2013) studied the consequences of incomplete implementation of BIM as is currently the case in most applications of the approach during design and construction stages. The study identifies three types of problems: process-based issues, technology-based issues and policy-based issues. The study then identifies the basic features of PLM in order to demonstrate the range of established solutions that address many of these problems. The results show that PLM can actually be an opportunity to expand existing applications of BIM. However, the study also suggests that the transverse application of a BIM-PLM solution based on discrete manufacturing processes might lead to other types of problems due to the complexity of interfaces observed in construction projects. Indeed, the problems observed in the use of BIM in construction are often specific to the client and the project's principal requirements, while the PLM approach is based on generic features. Moreover, the complexity and the large uncertainties of the collaborative environment in the construction industry suggest great caution. In the same period, Aram and Eastman (2013) proposed a discussion on the improvement of BIM with PLM functionalities. They noted that it should be necessary to modify and adapt many aspects of current PLM technology before being able to apply it in construction due to the major differences between the construction and the PLM's traditional target industries (Aram and Eastman, 2013).

Jupp and Nepal (2014) explored how BIM and PLM have impacted the professional practices in construction and manufacturing industries. For each industry, they explored the way BIM or PLM change the working practices through the new activities they come with, the new responsibilities and roles, the competencies needed and the relations in the supply chain. The study highlighted the unique characteristics of each industry and PLM and BIM contrasts. They concluded that the level of BIM maturity across the construction 
industry is improving, increasing the possibility to reach a "common endpoint with manufacturing industries." In the same spirit, Holzer (2014) noted that the full potential of the BIM approach has reached a maturity at a level that is possible to consider its integration, through the definition of BOM, with PLM systems and moreover with the production line. According to this research, the efforts undertaken in the past to link the manufacturing data with construction information in the frame of enterprise resource planning (ERP) systems have failed due to the use of 2D CAD that is not best suited for this purpose. With BIM, it is now possible to have the necessary information-centric project delivery approach. Therefore, it can be easier to integrate construction processes with product information. Parhiala et al. (2014) presented a comparison between BIM and digital mock-up (DMU) presented both as PLM technologies. Based on a literature review and focusing on operation and maintenance uses, the study shows how the two technologies apply similar functions for different industries and products. While the motivations of this research are valuable, the comparison of BIM (defined as 'building information modelling') with DMU is however questionable because the two concepts are different in scope and refer to different levels.

To complement these researches, many technology-centred works attempted to merge BIM and PLM capabilities into a single technological environment (Lebègue et al., 2014; Reefman and van Nederveen, 2011). If the effectiveness of these solutions remains to be seen, they have the merit of showing that a sum of features cannot be the solution to issues unresolved in the adoption of PLM, nor of BIM. More specifically, Ran and Singh explored in 2016 how BIM-enabled best practices in the Finnish construction industry could be used to improve the 3D CAD systems used in shipbuilding for better productivity. The study shows otherwise and the Finnish shipbuilding CAD tools were found to be more advanced than those used in construction. According to the results, the $3 \mathrm{D}$ coordination tools in shipbuilding showed better results than in BIM tools and the cost estimates in shipbuilding were more accurate. However, compared to the BIM-based scheduling practices in construction, the scheduling tools used in shipbuilding are less integrated with CAD systems. This study suggests that cross-pollination between the two approaches can benefit both construction and shipbuilding industries.

\subsection{Research approach}

The main objective of the research reported in this paper is to propose a factual comparison of BIM and PLM approaches. Based on the literature review presented in the previous section, it is clear that such a comparison can be done according to different perspectives including the five main components identified by Rumbaugh et al. (1991) for the study of innovations based on information technologies: hardware, software, data, people and processes. While it is important to compare them statically according to each of these perspectives, it seems even more useful to have a dynamic approach, taking into account the evolution through the different stages of the lifecycle. To be able to make such a comparison, it is not only necessary to identify a unifying concept linking the stages of the lifecycle, but also between the different actors involved. The bill of materials (BOM) and the PS appear to be able to play this role. Boton et al. (2016) have explored how these two concepts could be helpful for the comparison of the BIM and PLM approaches. Specifically, the research proposes to identify in the PLM and BIM approaches the concepts equivalent to the PS and the BOM, to understand their use 
throughout the product lifecycle and to describe the similitudes and the differences between them. The study was very meaningful but remains quite theoretical, as it does not use any specific industry on both sides to illustrate the comparison.

To ensure a consistent and reliable comparison with construction industry, the shipbuilding industry has been chosen in the research presented in this paper, to illustrate the use of PS and BOM in the PLM approach. Indeed, among the discrete manufacturing industries, shipbuilding industry is probably the closest to construction due to the uniqueness of the project requirements, site conditions and final product. Moreover, shipbuilding is different from the other industries "because of high customisation in design process and engineering software, widely varying scales of operations and less compatibility between different design and production processes" (Sharma and Kim, 2010). According to Sharma and Kim (2010), the production of a ship "is planned in activity-driven network scheduling system, in general and is assumed to be more of a construction process or assembly process rather than a production process." Finally, both construction and shipbuilding industries are considered to be engineering-to-order (ETO) industries, while aerospace and automotive are considered as assemble-to-order (ATO) and made-to-order (MTO) industries (Lee et al., 2012), even though aerospace is also considered as an ETO industry, especially at the completion stage when interiors are designed (Brière-Côté et al., 2010).

The paper focuses on the product (ship and building) BOL phases as defined by Terzi et al. (2010). Our work considers that both BIM and PLM are comparable approaches with similar intent as collaboration enablers. Both BIM and PLM are based on information technology and 3D models or DMUs, to represent and manipulate the 'product', be it a building or an aircraft. This distinguishes this research from other similar works such as Parhiala et al. (2014). We also consider that the 3D model (used to visualise the product), known in the construction industry as the building information model, as being roughly equivalent to the $D M U$ used in the aircraft or shipbuilding industries. This building information model or DMU is typically organised via different structures called product breakdown structure (PBS) or model element breakdown (MEB) in the BIM approach and PS in the PLM approach. Our aim is to conduct a comparison between the two industries, according to different parameters including the product, the main phases of the BOL, the product data model used, the existing hierarchical and enumerative classification systems, the formats of the outputs and the need for different views of the PS.

\section{Ship versus building BOL}

According to Terzi et al. (2010), the BOL is the part of the product lifecycle that encompasses design and manufacture. It is followed by the middle-of-life (distribution, use and support) and the end-of-life (product retirement in order to be disposed of or recycled). The BOL corresponds to the generation of the concept of the product and its physical realisation. Hence, just as Terzi et al. (2010), we do not consider here the project planning stage that usually comes prior to product's BOL. During the design phase, the requirements are identified, the concepts are defined, the detailed design is done, prototypes are developed and different tests are performed (Terzi et al., 2010). During the manufacturing phase, the artefacts are produced and "the product is in the hands of the company within the boundaries of the enterprise" (Terzi et al., 2010). In this paper, we 
focus on comparing shipbuilding and construction industries from the standpoint of PS during the BOL. Hence, in this section, we first examine the BOL in shipbuilding and in construction, respectively.

\subsection{Product BOL in shipbuilding}

The process of shipbuilding starts with the order to deliver and includes two main stages: design and manufacturing (Kim et al., 2002). The design stage encompasses the contractual arrangements with the owner, the basic design and manufacturing design. Basic design ensures that the ship owner's requirements are met. Manufacturing design is included within detail design. The design stage is followed by the manufacturing process, which includes many steps divided into erection (e.g., part fabrication, assembly, painting, etc.) and commissioning (e.g., launching, on-board outfitting, etc.). In regards to our specific research issue and for consistency reasons, we propose a simplified view of the product's BOL in the context of the shipbuilding industry (as shown in Figure 1), adapted from Kim et al. (2002) and Lee et al. (2012).

Figure 1 Simplified view of the product BOL in the shipbuilding industry (see online version for colours)

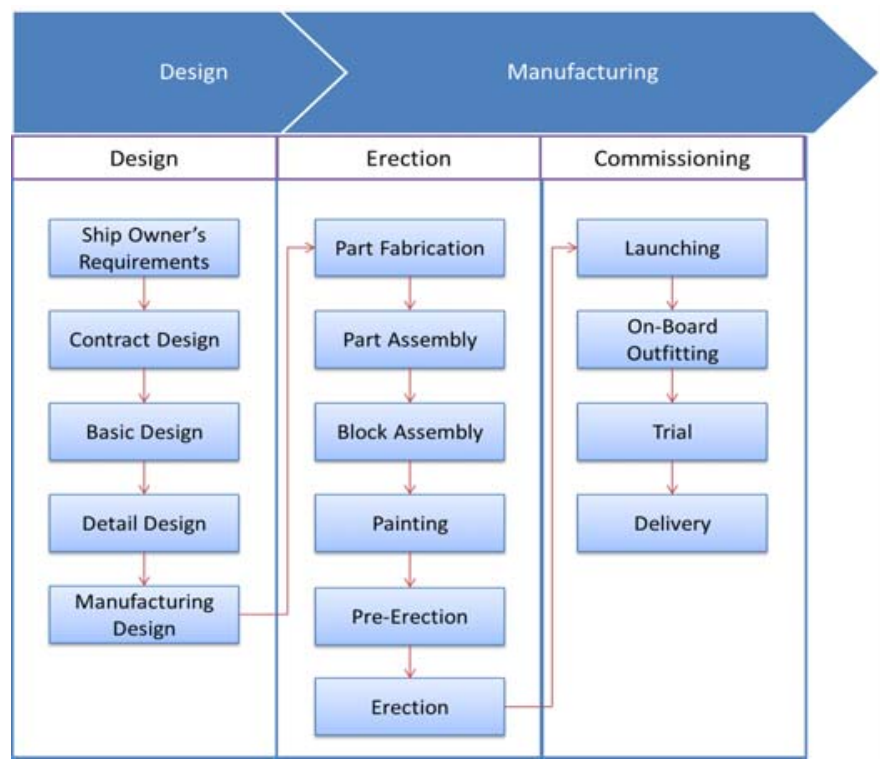

Source: Inspired from Kim et al. (2002) and Lee et al. (2012)

The original figure proposed by Kim et al. (2002) better illustrates the complexity of the process and shows how shipbuilding is different from other manufacturing industries. According to Kim et al. (2002), there are a number of underlying differences. The first one concerns diversity in the form and type of ship, which makes it challenging to standardise the design process. "The process of ship design deals with many techno-economic parameters that are conflicting in nature" (Sharma et al., 2012). Another reason is related to the beginning of the manufacturing and material procurement stages prior to the completion of the final design. This usually results in material replacement 
when changes are made by the engineers. Kim et al. (2002) also mention the labour intensive nature of the shipbuilding industry, with a low rate of automation and mechanisation, as well as the difficulty to achieve manufacturing standardisation due to the complexity of the industry structure. They finally note the contrast between the high accuracy required and the size of the material used and the quantity of information required to manage the specifications of each individual ship. While some of these observations could apply to other manufacturing industries, such as aerospace, we consider that their applicability to the construction industry is significant. Hence, comparing shipbuilding and construction industries is a promising avenue for the comparison of PLM and BIM.

\subsection{Product BOL in construction}

The development of a construction project, as any project, encompasses different stages. Here, we review the BOL stage of a typical construction project to establish a basis for comparing with the shipbuilding BOL stages. Boton (2013) noted that several decompositions of these stages exist throughout the project lifecycle. For example, Boton (2013) proposed to consider four main stages: pre-project (assembly, feasibility study and search for financing), pre-construction (design, allotment, allocation of lots, site preparation), construction (construction of the facility) and post-construction (commissioning, operation, rehabilitation or demolition). However, Succar (2009) summarises the construction project lifecycle in three main stages: design, construction and operation. The 2013s version of the Plan of Work proposed by the Royal Institute of British Architects (RIBA, 2013a) identifies seven main stages: strategic definition, preparation and brief, concept design, developed design, technical design, construction, handover and close out and in use stages. These stages are similar to the ones generally considered by the Computer Integrated Construction (CIC) research group: brief, concept, developed design, production, installation, as constructed and in use.

Based on these different sources, we can consider in the framework of this paper that the BOL of the facility in a traditional delivery method corresponds to the design and construction stages (Figure 2). The design stage involves the design and bidding phases. The design encompasses the preparation, the concept design, the developed design, the technical design and the specialist design (RIBA, 2013b). The construction stage involves the construction and the commissioning phases. The construction phase involves the site preparation, the earthworks, the foundation and the shell erection, the mechanical, electrical and plumbing (MEP) activities and the finishing works. The commissioning phase encompasses as-built documents, commissioning and handover.

It is important to note that the process is far from being so linear in real life. Indeed, construction projects have particular properties that make their management quite complex. Among these peculiarities, Baccarini (1996) points to the existence and commitment of several diverse and separate organisations, requiring the establishment of temporary organisational structures and contractual forms varying from one project to another. Sunke (2009) focuses on eight properties to be taken into account about construction specifics, including the changing production sites, the spatial constraints, the dependence on seasons and weather conditions, the construction-specific (and often country-specific) legislation and the very uncertain planning environment. 
Figure 2 Traditional view of the product BOL in the construction industry (see online version for colours)

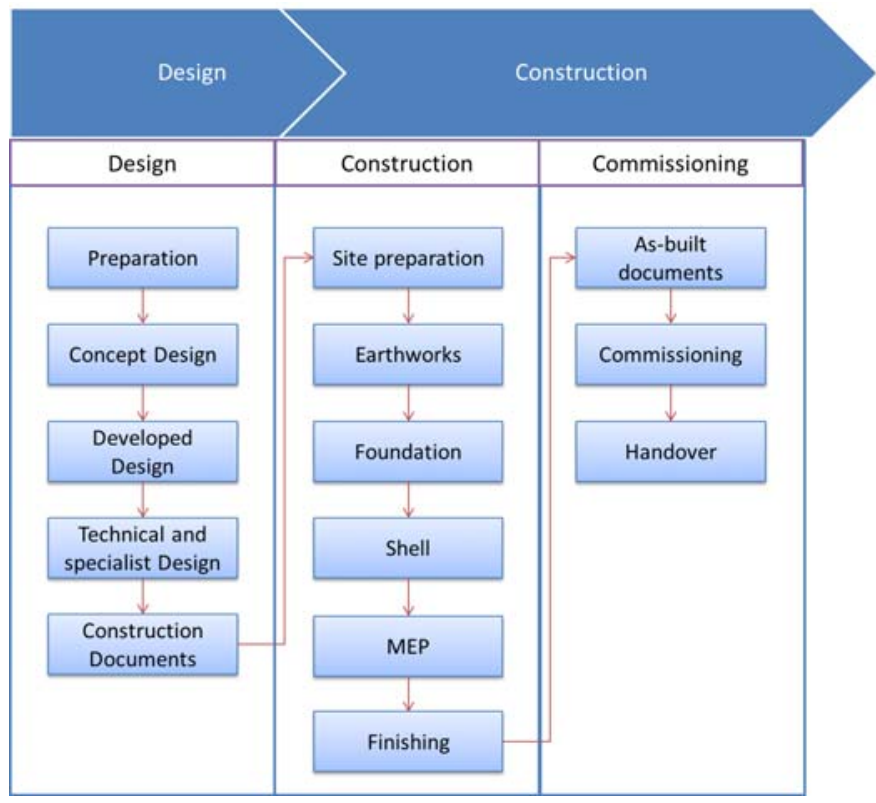

This study of the shipbuilding and construction BOL stages shows that the project steps are comparable but not identical in the two industries. In light of the similarities and differences between these stages and steps, we can explore how the concepts of the BOM and PS are used - firstly, in the context of shipbuilding and then in construction.

\section{$4 \quad$ PS and BOM in shipbuilding}

Now that the shipbuilding and construction industries' BOL stages and steps have been described, we next examine the role of the BOM and PS (or comparable product descriptions), in both industries. This section focuses on shipbuilding.

\subsection{Definition of concepts}

The BOM can be defined as 'a list of ingredients' (Stark, 2016), or as "a list of components required for the production of a parent item" (Jansen-Vullers et al., 2003). The latter describe the BOM as a network of 'goes-into' relationships established between a component item and a parent item. Items are nodes described by their identification number. Each relationship stores the number of component units necessary for the parent unit, as well as (potentially) other data such as 'effectivity' dates (dates that define when a particular part or item is used to build the parent unit) (Jansen-Vullers et al., 2003).

Thus, the BOM details all of the materials or components that go into a product such as quantities, sub-assemblies and variations within assemblies and permissible substitutions. The BOM can be managed according to different views on the product 
(Schuh et al., 2008). Hence, the engineering BOM (eBOM) describes 'what' the product is while the manufacturing $\mathrm{BOM}(\mathrm{mBOM})$ describes 'how' the product is produced and assembled (Essamlali et al., 2015). Maull et al. (1992) distinguish different production environments including: 'make-to-stock (MTS)', 'ATO', 'MTO' and 'engineer-to-order'. Each environment demands specific BOM structures. Moreover, many different BOMs are needed within a single environment. For example, in 'MTO' environments, four different BOMs are used: a planning BOM for forecasting purposes (relationships between product families and components), a standard BOM (semi-finished products released from engineering), a reference BOM (kinds of the product) and an order BOM (associated to a particular customer orders). In 'engineer-to-order' environments, the BOM is developed gradually. Maull et al. (1992) also indicate that "it is common practice for customers to change specification during the lifetime of the product." BOMs usually begin in the design-engineering department but are found in the inventory control, procurement, shipping, marketing, manufacturing, field services and even in the accounting department (Saaksvuori and Immonen, 2008). Hence, the BOM is represented in various ways depending on the environment and on the stage of development of a project. An example of a BOM is presented in Figure 3. It can be noted that the BOM is usually managed by the PLM system, which also manages the link between a component in the BOM and its geometric representation.

Figure 3 Example of BOM for a scooter in 3DExperience (see online version for colours)

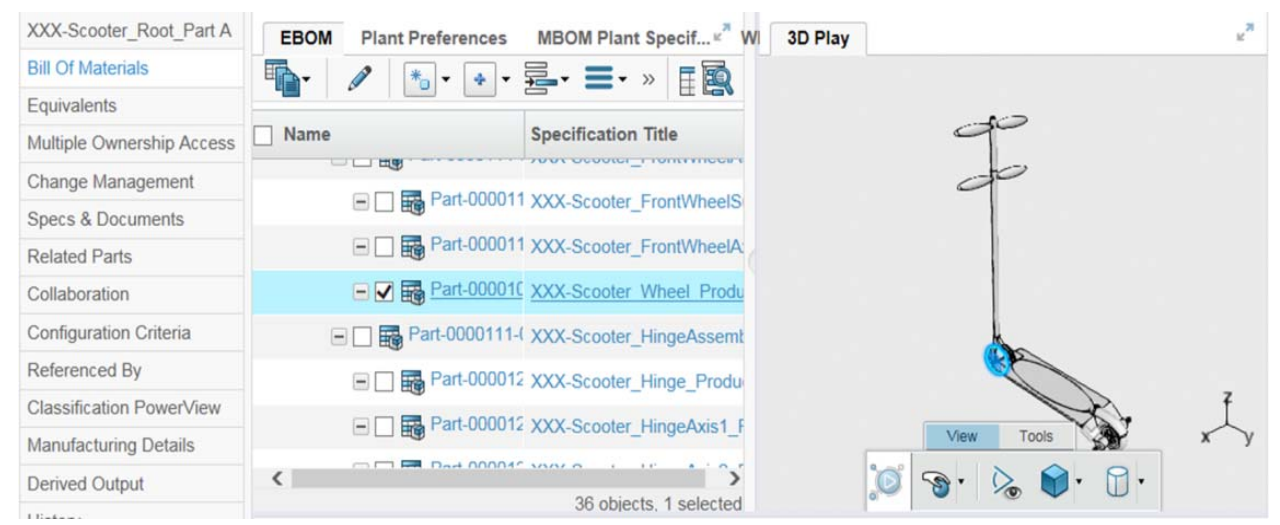

Note: Courtesy of Dassault Systemes.

There should be no confusion of the BOM with the PS even if, in colloquial language, a BOM is often referred to as a PS (Saaksvuori and Immonen, 2008). Eynard et al. (2004) note that all 'instantiated data' are managed and stored in the PS. According to Brière-Côté et al. (2010), these two concepts, BOM and PS, differ despite their similarity. PS simultaneously handles the product hierarchy and the product views, as described by Van den Hamer and Lepoeter (1996). The concept of hierarchy relates to the semantics of composition, captured using the 'part-of' relationship between objects. The concept of view rather relates to the semantics of equivalence, where two views describe the same object.

Two modelling approaches have been identified by Van den Hamer and Lepoeter (1996) in order to manage both semantics: the 'level-by-level' model and the 'non-isomorphic hierarchies' model. As stated by Brière-Côté et al. (2010), the level-by- 
level model is based on the assumption that all of the views can agree on and connect to common product decomposition. Alternatively, the non-isomorphic hierarchies' model allows each view to develop its own PS (Figure 4). This type of model appears to be more pragmatic, according to observations of industrial practices and case studies (Svensson and Malmqvist, 2002). In both cases, the PS is organised so as to feed different views of the product definition in a (hopefully) coherent manner.

Figure 4 Non-isomorphic hierarchies' model

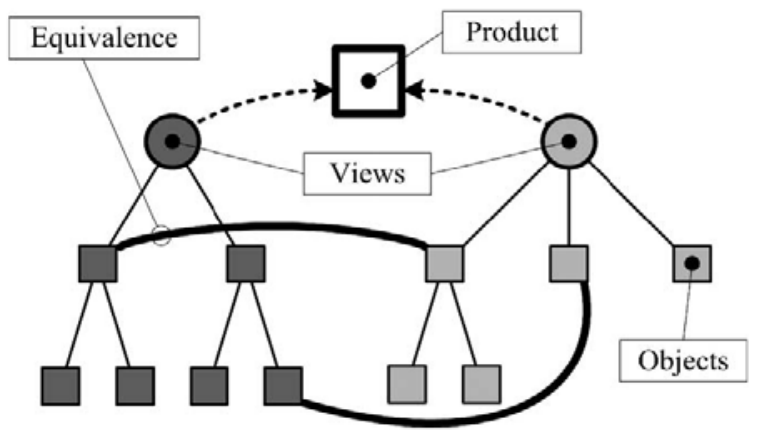

Source: Brière-Côté et al. (2010)

Figure 5 Example of a multi-view PS (see online version for colours)

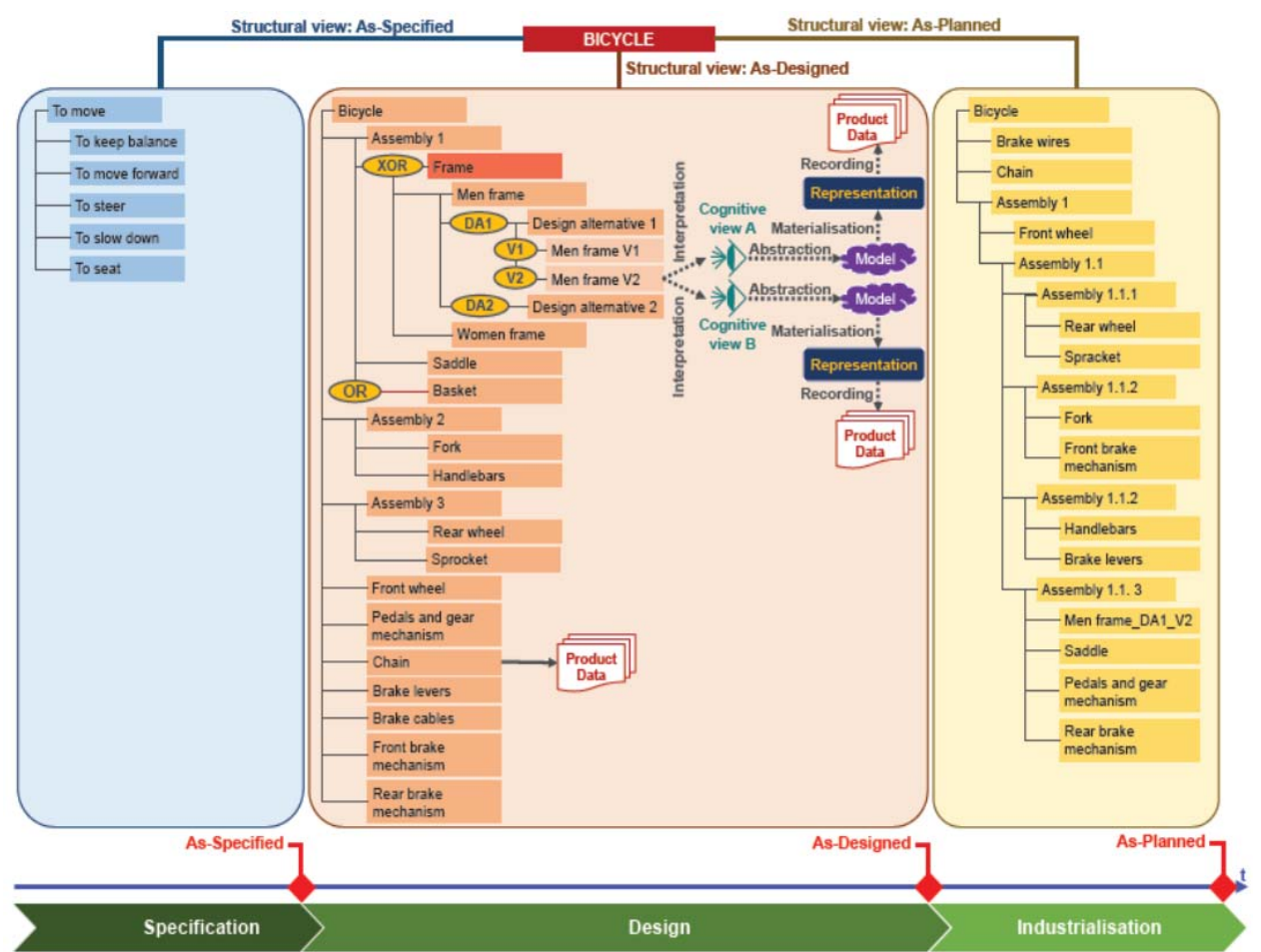

Source: Pinquié et al. (2015) 
According to Pinquié et al. (2015), a PS is an organised hierarchical classification of technical objects with their associated product data. A 'technical object' basically corresponds to a node in the structure, while the nature of the node differs depending on the point of view. As explained by Pinquié et al (1995), based on Maurino (1995), for the engineering team, a technical object is an 'item', be it a component, a sub-assembly or assembly. For the product specification, a technical object would be a function rather than an item. From a manufacturing standpoint, the technical object could be a tool required for assembling. Thus, the PS captures relationships not only between technical objects, but also with data defining it. This data materialises as files with revisions and versions. Moreover, according to Pinquié et al. (2015), a PS can store an entire customised products family, the different design alternatives, as well as the successive product data versions and revisions. Figure 5 exemplifies these notions of a structured view of as-specified, as-designed and as-planned technical objects, product data and customised product families. This of course implies managing effectivities, typically through the relationship between objects of the structure. Hence, a BOM, as a single-level part list, is considered as a simple filtered PS snapshot at some point during the life of the product's development (Pinquié et al., 2015).

In PLM systems, these data are classified using metadata and appropriate links are established between the technical objet (such as parts) and related files through metadata configurable link (Eynard et al., 2004). In practice, the PS can encompass various data types - such as specification documents or geometric representations of a given part - as shown in the example of the multi-view PS shown in Figure 5. Trappey et al. (1996) identified at least ten major data types and functions including product definition, service parts support, material purchase planning, assembly sequence, order entry facility, resource analysis, pricing, cost analysis, manufacturing instruction and engineering change control. For product design and manufacturing management purposes, PLM systems offer, in addition to the PS manager, a workflow engine which "according to the product structure, sends the right available data at the right time to the right user" (Eynard et al., 2004). This constitutes an important aspect in optimising the information flow in the PLM approach.

\subsection{BOM and PS in shipbuilding BOL}

According to Lee et al. (2012), while PLM and BOM have been well adopted in shipbuilding, the nature of this industry led to using BOM management approaches that differ from those of other industries. Indeed, Lee et al. (2012) distinguished MTS, the MTO and the ATO industries, such as aerospace and automotive, from the ETO industries like construction and shipbuilding. In MTO and ATO industries, a modular BOM is "explicitly defined prior to manufacturing execution" and used "with a high emphasis on variant traceability" (Lee et al., 2012). In shipbuilding, the BOM is "gradually developed during the project lifecycle, with less emphasis on variants". 
Figure 6 Schematic configuration of outfitting ship BOM along the lifecycle

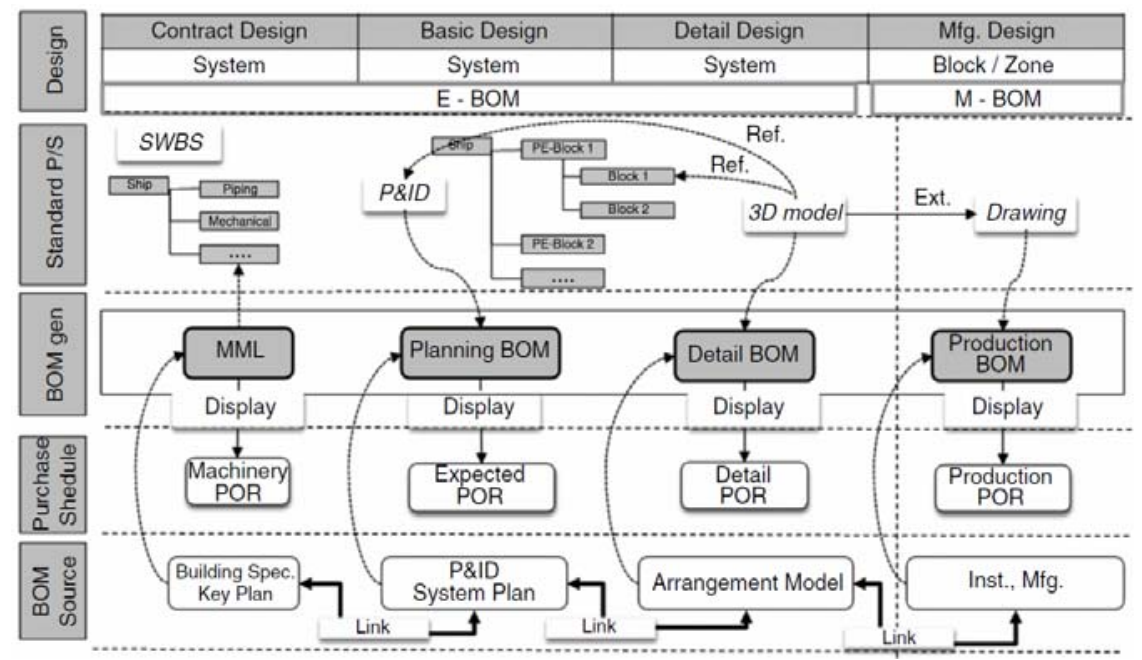

Source: Lee et al. (2012)

Figure 7 Example of SWBS for container ship in basic design (see online version for colours)

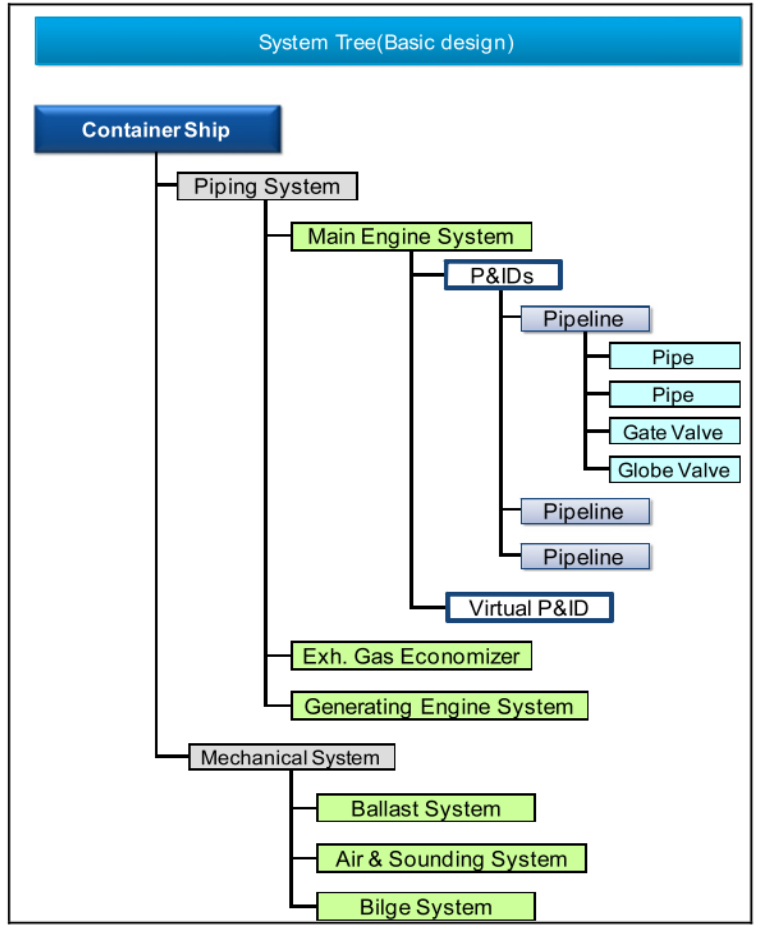

Source: Lee et al. (2012) 
In shipbuilding, as in other industries and as mentioned above, the definition of the BOMs is undertaken in such a way that it could represent multiple disciplines during the lifecycle of the product. Different views of the BOM are generated according to specific needs related to the project phase. Figure 6 hence shows the referential trees and BOMs in the different views of PS relative to each design phase and the corresponding sources of the BOM from which it is extracted. At the initial (contract) design phase, a main machinery list (MML) serves as a BOM. It comes from the building specifications key plan and is built based on the system work breakdown structure (SWBS) (see Figure 7), "which is composed of the functional unit of the outfitting equipment", decomposing the ship into systems. In the basic design phase, the eBOM is generated from the planning BOM and the piping and instrumental diagram (P\&ID) system plan. In the detail design phase, the 3D models available make it possible to generate a detail BOM. A production $\mathrm{BOM}$ is generated at the manufacturing design phase. This is intended to track BOM changes and the nature of the types of purchase order requests (PORs) used to transfer the BOM to the material requirement planning (MRP) or ERP systems (Lee et al., 2012).

Figure 8 Evolution of referential PSs associated with BOM (see online version for colours)

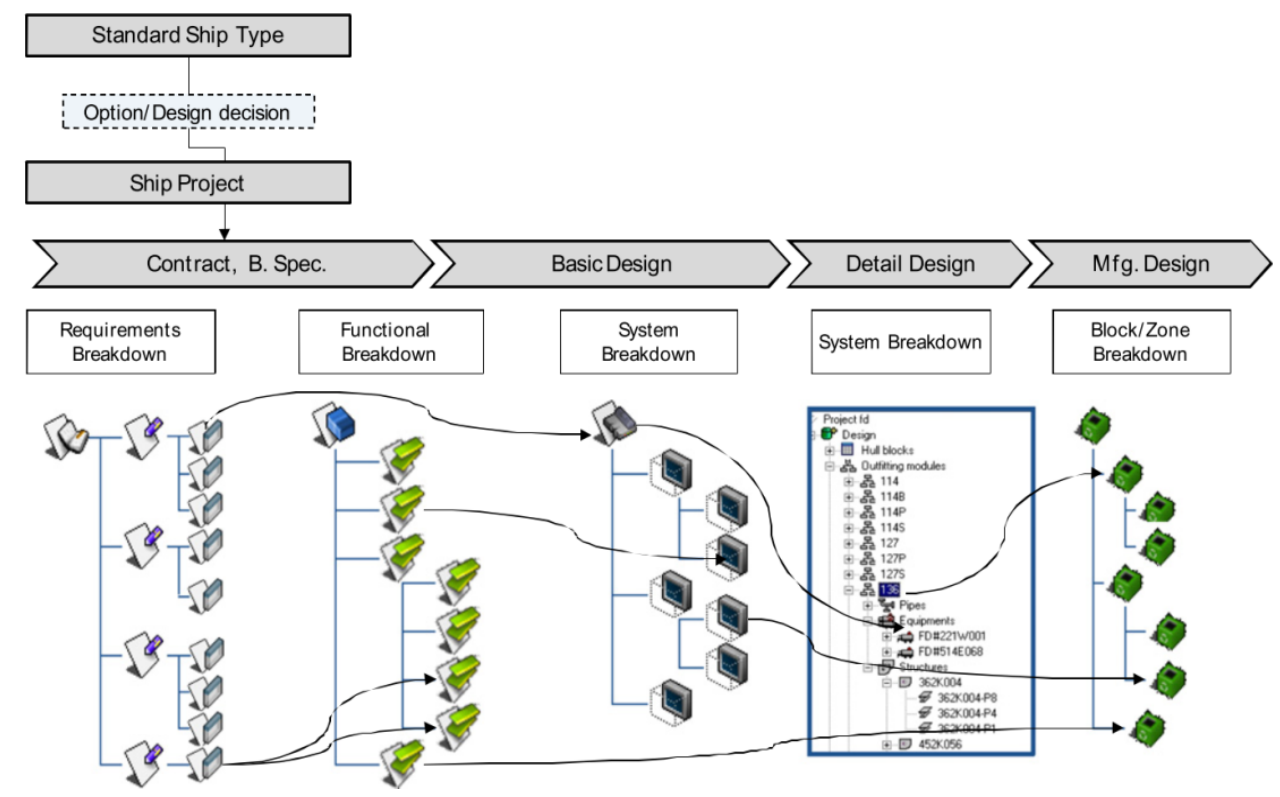

Source: Lee et al. (2012)

It is important for the PS to express the BOM variations in order to make it possible to highlight how an early stage generated BOM can evolve from this stage towards the production stages (Lee et al., 2012). Figure 8 illustrates the evolution of referential PSs proposed by Lee et al. (2012), depicting its evolution according to the project phases and the corresponding evolution of the BOM. 


\section{Some background on construction industry for comparison with shipbuilding}

\subsection{Traditional building product classification systems}

Before further examining how these concepts apply in the context of BIM-enabled construction projects, it is important to first discuss the classification systems used to describe the built environment. Indeed in the construction industry, "it is critical to use classification systems when dealing with specifications, structuring of documents and cost estimation" (Afsari and Eastman, 2016). Many systems have then been developed with different purposes, terminologies and semantics. Some of the most known classification systems are Omniclass, UniFormat and MasterFormat.

The OmniClass construction classification system (OCCS) is established for organising all construction information. OmniClass is supported by Construction Specifications Institute (CSI) and Construction Specifications Canada (CSC). Various editions of OmniClass and its predecessor tables which include UniFormat and MasterFormat, are widely used across North America (Gelder, 2013). The popularity of OmniClass surrounds its use within the US National BIM Standard (Brodt, 2016).

The UniFormat classification system organises the construction information "into categories such as foundation, superstructure, shell and interior construction and into subcategories such as floor and roof construction and exterior walls and windows" (Sabol, 2008). The classification is made "around the physical parts of a facility called systems and assemblies known as functional elements. These systems and assemblies are characterised by their function without identifying the work result" (Afsari and Eastman, 2016). Such classification systems are "suitable for applications including cost control and schematic phase preliminary project descriptions" (Afsari and Eastman, 2016). It is then used to generate cost estimates "in the preliminary phases of the project. [...] The format, by itself, will be too general to categorise components for detailed cost estimates" (Sabol, 2008).

Produced by the CSC and the CSI, MasterFormat provides a hierarchical and enumerative classification system to organise the information related to a construction work (Afsari and Eastman, 2016). MasterFormat is "generally used during the construction documentation phases of a building project, when detailed information is developed and organised" (Sabol, 2008) and mostly "in bidding and specifications" (Afsari and Eastman, 2016). Figure 9 proposed by Sabol (2008) shows how a wall detail is classified according to UniFormat and MasterFormat. In this example, the code B2010 designates an 'exterior wall' according to the UniFormat classification, while MasterFormat codes describe the wall components as a greater level of details.

While UniFormat and MasterFormat classification systems are well known and widely used in the North American construction context, the successor classification system, Omniclass, is also used around the world. However, Uniclass, BSAB and DBK have become the main classification systems used respectively in the UK, Sweden and Denmark (Afsari and Eastman, 2016). This makes it difficult "to have a structured guideline for combining classification systems in international scale" (Afsari and Eastman, 2016). 
Figure 9 Wall detail and classification by UniFormat and MasterFormat (see online version for colours)

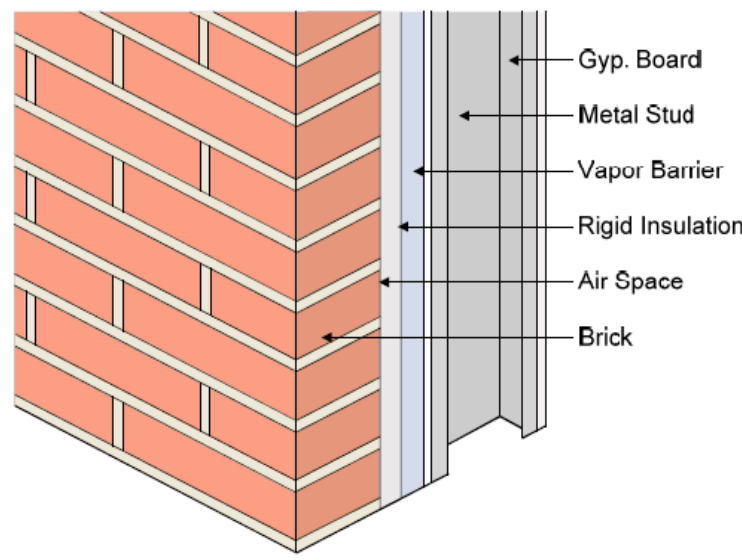

\begin{tabular}{|l|c|l|l|l|}
\hline UniFormat & MasterFormat & & & \\
\hline & & Components & Type & Size \\
\hline B2010 & & & & \\
\hline & 4210 & Brick & Modular & \\
\hline & & Air Space & & $1 "$ \\
\hline & 7210 & Insulation & Rigid & $11 / 2 "$ \\
\hline & 7260 & Vapor Barrier & Felt & $15 \#$ \\
\hline & 6160 & Sheathing & & $5 / 8 "$ \\
\hline & 5410 & Metal Stud & Galvanized & $31 / 2$ '" \\
\hline & 9250 & Gyp. Board & Type 'X', WP & $5 / 8$ " \\
\hline
\end{tabular}

Source: Sabol (2008)

In fact, the choice of a classification system is dependent on the purpose of classifying building systems, materials or products. For example:

- For the classification of building systems, UniFormat and Omniclass Table 21 dominate in North America whereas Uniclass 2015 Table Ss (systems) is the preferred convention in the UK. Both classification schemas support preliminary design activities including cost estimates. They provide the information in a structure suited to what the architects and structural engineers want or need to know.

- For the classification of building materials, MasterFormat and Omniclass Table 22 dominate in North America whereas Uniclass 2015 Table En (entities) is the preferred schema in the UK. Both classification schemas support the organisation of the work to be executed and provide the information in a structure suited to what the contractor and subcontractors want or need to know.

- For the classification of building products, Omniclass Table 23 dominates in North America whereas Uniclass 2015 Table Pr (products) is the preferred system in the UK. While both classification schemas support the classification of specific items, Omniclass is limited due to its strictly hierarchical nature and as a result, it is more difficult to extend in a consistent way.

Sabol (2008) provides an overview of the use of these different classification systems according to the lifecycle phase (Figure 10). These classification standards are primarily 
used during design and are directed towards supporting the onsite integration of equipment within the building. More recent classification systems aimed at the operations and maintenance phases are gaining traction in industry. An example of a state-of-the-art naming convention is Project Haystack, which has developed an open set of tags for naming key building automation and energy components (Project Haystack, http://project-haystack.org/).

Figure 10 Construction information standards by phase (see online version for colours)

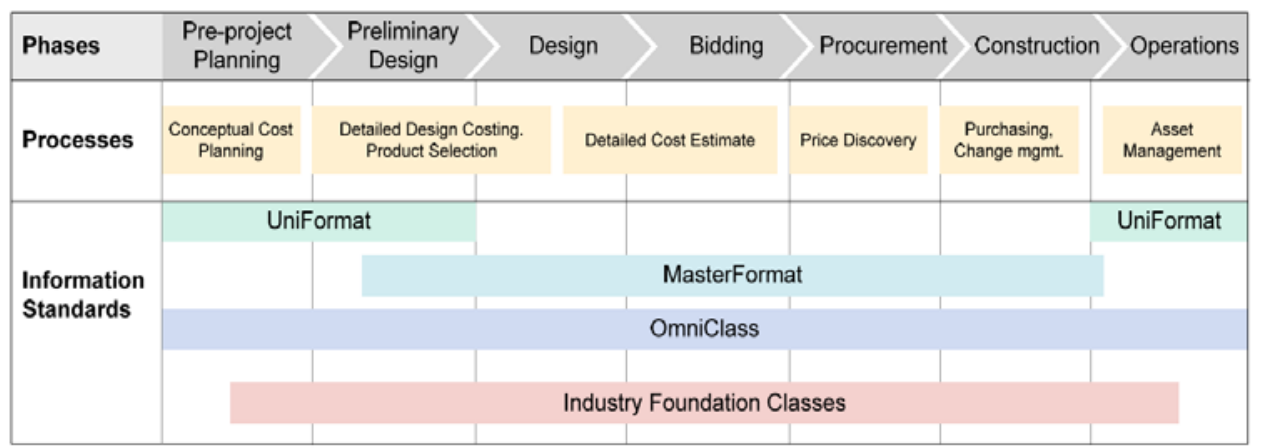

Source: Sabol (2008)

\subsection{BIM and its impact on product BOL}

The BIM approach consists of developing, using and transferring an information-rich 3D object-oriented model of a built facility to improve its design, construction and operation. The IFC standard has been developed to support the data exchanges between different software. It consists in a data model for the construction industry, which covers several disciplines including AECO (East et al., 2013). In the implementation of this standard, it is recommended to use model view definition (MVD) to structure the exchanges and the data to be manipulated by users. A MVD is a subset of the IFC schema which documents the data structures adapted to a particular discipline (East et al., 2013).

If the first research works have focused on the technological aspects of the BIM approach, recent findings suggest that the challenges to overcome are related not only to technology, but mainly to organisation procedures, BIM project standards and processes (Homayouni et al., 2010; Jupp, 2013; Shafiq et al., 2013). Three levels of BIM maturity have been identified (Succar, 2009). The first level (stage 1) is limited to the use of object-based modelling software. At this level, the traditional dimensional drawings are replaced by $3 \mathrm{D}$ models that are augmented with semantic information. The second level (stage 2) adds model-based collaboration in order to better formalise and support the information exchange between the multidisciplinary actors involved in the construction project. At the third maturity level (stage 3), a full network-based integration is setup in order to be able to collaboratively create, share and maintain a multidisciplinary integrated model across the project lifecycle.

As shown by Succar (2009), according to the maturity level of BIM, the information exchange does not occur in the same conditions (Figure 11). Most of the current BIM practices can be situated at the two first levels. One of the main reasons is related to the delivery methods used in construction project. Indeed, while many studies have shown 
that shared risks-based methods such as integrated project delivery (IPD) are best suited to the stage 3 , it is difficult for owners (especially public owners) to change contracting practices and the traditional 'design-bid-build' is still the most widely used, which is not necessarily a guarantee of good results when using the BIM approach.

Figure 11 Project lifecycle phases according to the BIM maturity and delivery methods (see online version for colours)

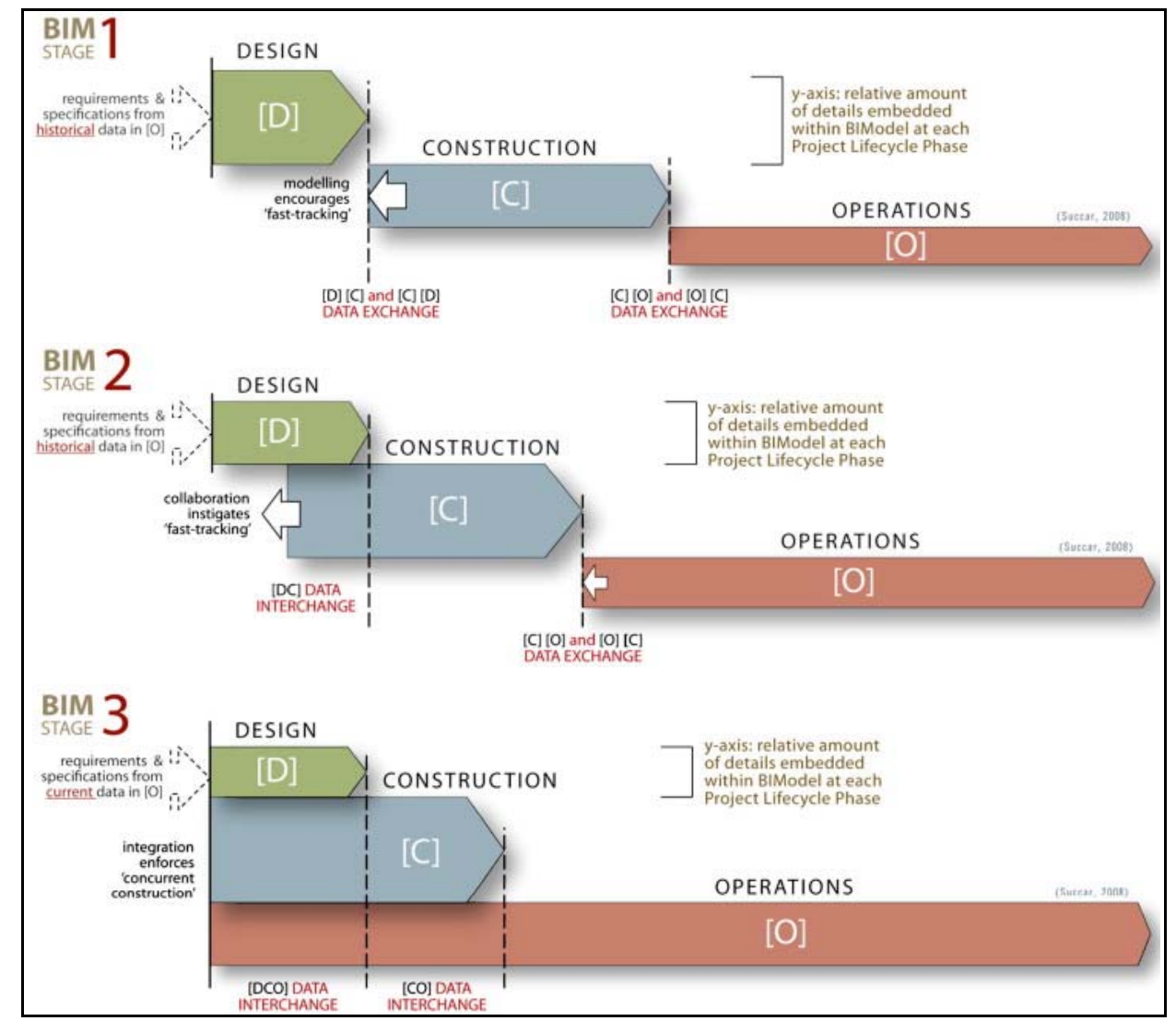

Source: Succar (2009)

The most used project delivery method is design-bid-build. In this method, the complete construction documents are produced by the engineers and the architects before involving the builder. The lowest bid among bidding contractors is chosen to complete the construction work, under the monitoring of the architect. Design-build and construction management methods are also well-known but less used in the industry. In the design-build method, "the owner contracts with a firm that supplies and/or coordinates the design and construction functions" (Chelson, 2010). In the construction management method, "the owner contracts with the architect and builder, but the builder is selected based on qualifications during the design phase so that it can perform constructability reviews" (Chelson, 2010). 
Whatever the project delivery method is, information exchange is critical during the project phases. In Section 6, we explore the equivalent concepts to BOM and PS under the BIM approach.

\section{Concepts comparable to PS and BOM in BIM-based construction}

To ensure that the appropriate information is contained within the BIM model, current practices suggest identifying the function of the model and specify the BIM uses and related information requirements prior to implementation to develop the model accordingly. Kreider and Messner (2013) define 'BIM use' as "a method or strategy of applying building information modelling during a facility's lifecycle to achieve one or more specific objectives." Twenty-five BIM uses have been identified (e.g., 3D coordination, design review, cost estimation, phase planning, site analysis, mechanical analysis, etc.) with various use frequencies and different impacts in the industry (Kreider et al., 2010). Similarly, Succar et al. (2016) have defined a 'model uses' concept, comprising of a 'model uses taxonomy' and a 'model uses list' so as to describe the "intended, planned, or expected project deliverables resulting from generating, collaborating, or linking models to external databases." Hence, BIM or model uses are in essence 'use cases'. In this sense, the construction discipline experts are then able to specify the information delivery manuals (IDM) from which the specific MVDs can be prepared by information experts (Eastman et al., 2010).

BuildingSMART promotes a number of different MVDs. The IFC2x3 Coordination view 2.0 supports the coordination activities between architecture, MEP and structural engineering models at the design phase. The IFC $2 \times 3$ structural analysis view supports the exchange of the structural model between different structural design and analysis software. The IFC2 33 basic FM handover view covers the exchange of the required information with $\mathrm{CAFM}^{1}$ and $\mathrm{CMMS}^{2}$ applications. $\mathrm{COBie}^{3}$ was first proposed by the US Army Corp of Engineers in 2007 (East and Brodt, 2007) and was adopted in 2014 as a British standard (Pärn et al., 2017), playing a significant role in the UK Government's BIM strategy (BSI, 2014). Its development is aimed at identifying the information exchange needs for facility management handover and at facilitating the collection and transfer of information throughout the project lifecycle (East et al., 2013). In the UK Government BIM strategy, COBie is a 'checking tool' used to "validate asset and space information at set stages during the design, build and operation of a building" (AEC Magazine, 2014). It is then possible to convey the required information from the BIM model to CAFM applications using the COBie schema. It commonly takes the form of an Excel spreadsheet which typically contains 21 tabs, multiple rows with different colours: the required fields are represented in yellow while the optional ones are in green. Orange, purple and grey colours are also used to represent respectively references to other lists, external references and secondary information (AEC Magazine, 2014). Each tab in the spreadsheet represents the categories in which the BIM data is broken according to the structure of COBie: facility, floor, zones, rooms, type, objects, components, systems (M\&E) and assemblies. Figure 12 from BSI (2014) shows an example of the information contained in the type tab. 
Figure 12 COBie type example (see online version for colours)

\begin{tabular}{|c|c|c|}
\hline Type & Example & Notes \\
\hline Name & White Board & expected \\
\hline CreatedBy & name@email.com & reference \\
\hline CreatedOn & 2013-04-15T00:00:00 & expected \\
\hline Category & L76134:Presentation systems & pick \\
\hline Description & Short Throw Projector & expected \\
\hline AssetType & Fixed & pick \\
\hline Manufacturer & company@email.com & reference \\
\hline ModelNumber & 587 & expected \\
\hline WarrantyGuarantorParts & company@email.com & reference \\
\hline WarrantyDurationParts & 5 & expected \\
\hline WarrantyGuarantorLabor & company@email.com & reference \\
\hline WarrantyDurationLabor & 5 & expected \\
\hline WarrantyDurationUnit & Year & pick \\
\hline ExtSystem & Authoring Application & application \\
\hline ExtObject & IfcFurnitureType & application \\
\hline Extldentifier & 1/Ts7iOoDD\$830Kgut03mv & application \\
\hline ReplacementCost & 2760 & requirable \\
\hline ExpectedLife & 15 & requirable \\
\hline DurationUnit & year & pick \\
\hline WarrantyDescription & $\begin{array}{l}\text { Onsite warranty and advanced } \\
\text { replacement warranty }\end{array}$ & requirable \\
\hline NominalLength & 2105 & expected \\
\hline NominalWidth & 50 & expected \\
\hline NominalHeight & 1329 & expected \\
\hline ModelReference & Short Throw Projector & requirable \\
\hline Shape & rectangular & requirable \\
\hline Size & $2105 \mathrm{~mm} \times 1329 \mathrm{~mm}$ & requirable \\
\hline Color & white & requirable \\
\hline Finish & matt & requirable \\
\hline Grade & tough & requirable \\
\hline Material & various & requirable \\
\hline Constituents & remote controller & requirable \\
\hline Features & auto-shutdown & requirable \\
\hline AccessibilityPerformance & visual impairment adapted & requirable \\
\hline CodePerformance & fully earthed & requirable \\
\hline SustainabilityPerformance & low-energy & requirable \\
\hline
\end{tabular}

Source: BSI (2014)

Another interesting concept in the current BIM approach with regards to our particular research issue is the model element table (MET). At the starting of a BIM project, an ad hoc MET is defined in order to identify information requirements of the project. The MET structure in construction is quite similar to the BOM in manufacture. It summarises the list of the model elements but also "indicates the level of development (LOD) to which each model element author (MEA) is required to develop the content of the model element at the conclusion of each phase of the project" (AIA, 2008). Figure 13 shows how the building elements are structured in the MET to enable the definition of the required LOD and to indicate the MEA responsible. The MET serves as basis for the development of the BIM model. A concept similar to MET is the information exchange worksheet proposed by the Pennsylvania State University (The Computer Integrated Construction Research Group, 2011). 
Figure 13 Excerpt of a MET (see online version for colours)

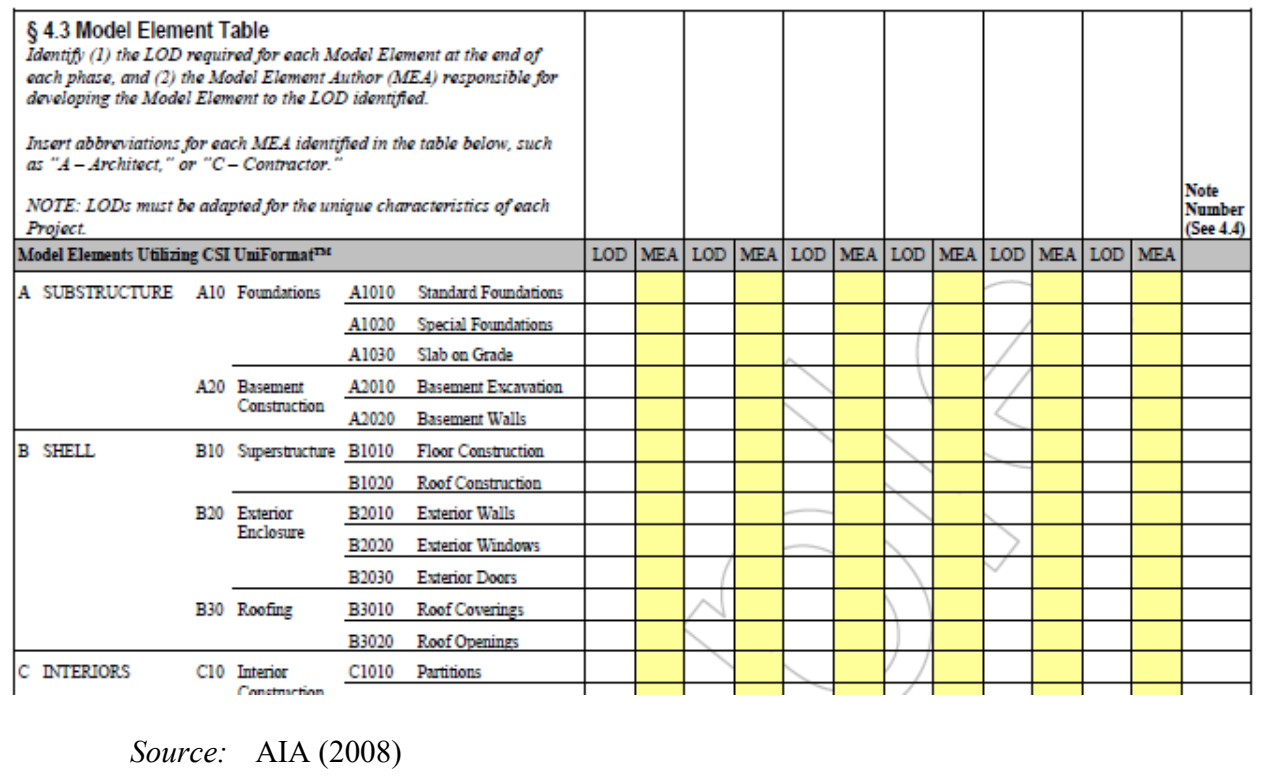

The BIM model is then developed according to the requirements defined in the MET. In current 3D model authoring and model compilation tools, it is possible to generate a hierarchical list of model elements and many of the concepts of hierarchy relating to the semantics of composition, e.g., captured using the 'part-of' relationship between objects which are key to the shipbuilding industry's application of PS are similar, including the PBS and the MEB. According to Gijezen et al. (2010), the PBS "divides the final object in physical systems, components and elements." The PBS concept is well known in the BIM approach. For example, it plays an important role in 4D simulation where the model creation consists of linking it with the work breakdown structure (WBS) from the schedule (Zhou et al., 2009). Moreover Gijezen et al. (2010) showed how the PBS could be used to improve the clash detection process in $3 \mathrm{D}$ coordination. In $3 \mathrm{D}$ model authoring software, it is also known as the MEB, as described by Saluja (2009), which can be used to create information exchange worksheets. Figure 14 illustrates how, in a BIM software, the MEB organises the components of the 3D model of the building and links them to their geometry.

The above mentioned data structures and reference views do not manage quantities. Hence, another representation available in $3 \mathrm{D}$ model authoring and model compilation tools is the bill of quantities, resulting from the quantity take-off process. The bill of quantities is used, typically, to estimate material costs (i.e., a partial 5D model). In Revit, for example, the bill of quantities is materialised as 'schedule/quantities', such as shown in Figure 15. Figure 15 shows the number of interior doors located on the ground floor level of the building model. 
Figure 14 Example from Navisworks of the link between a component from the MEB and its $3 \mathrm{D}$ model (see online version for colours)

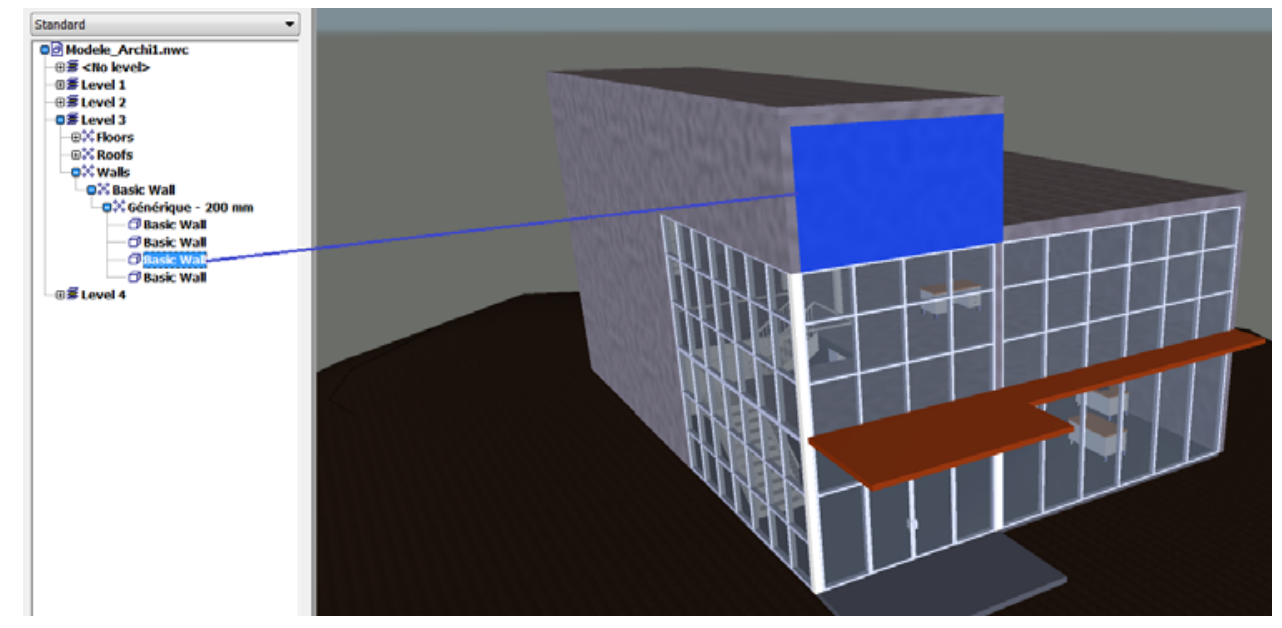

Figure 15 Example of bill of quantities generated in Revit

\begin{tabular}{|c|c|c|c|c|}
\hline A & B & $\mathrm{C}$ & D & $\mathrm{E}$ \\
\hline Type & Uniformat & Width (m) & Height (m) & Quantity \\
\hline $\mathrm{P} 2-0915 \times 2032 \mathrm{~mm}$ & C102001 & 0,915 & 2,032 & 2 \\
\hline P3-0915 × $2032 \mathrm{~mm}$ & C102001 & 0,915 & 2,032 & 1 \\
\hline P8-0915 × $2032 \mathrm{~mm}$ & C102001 & 0,915 & 2,032 & 1 \\
\hline P13-0915 × $2032 \mathrm{~mm}$ & C102001 & 0,915 & 2,032 & 5 \\
\hline P14-0915 × $2032 \mathrm{~mm}$ & C102001 & 0,915 & 2,032 & 2 \\
\hline P15-0915 × $2032 \mathrm{~mm}$ & C102001 & 0,915 & 2,032 & 3 \\
\hline P16-0915 × $2032 \mathrm{~mm}$ & C102001 & 0,915 & 2,032 & 1 \\
\hline P19-0915 × $2032 \mathrm{~mm}$ & C102001 & 0,915 & 2,032 & 4 \\
\hline $\mathrm{P} 21-1830 \times 2032 \mathrm{~mm}$ & C102001 & 1,8300 & 2,032 & 1 \\
\hline
\end{tabular}

In Figure 16, we summarise these three different concepts including classification systems, hierarchical relationships and model use and view definitions according to the BOL steps that map on to the RIBA Plan of Works (RIBA, 2013a) and Sabol's (2008) project stages. In the first row, the use of the classifications systems is shown, using the case of the Canadian construction industry where UniFormat and MasterFormat are largely used and where Omniclass is less known. While UniFormat is used in schematic design and design development steps, MasterFormat tends to be more widely used for construction documents, bidding and construction phases.

The second row reflects the BIM exchange documentation. To meet the challenge of defining what information is needed, from whom and at what level of detail several international specifications aim to address the definition of modelled objects and information embedded within them (Bolpagni and Ciribini, 2016). These definitions are typically specified within the BIM execution plan, also known as a BIM management plan. Within these plans, the MET and the model attribute table are used to progressively specify modelled objects and the information embedded within them. These specifications are developed at the beginning of the project and are progressively defined throughout design development and used until the construction documents are issued. To 
support this process a number of progressive model development methodologies and protocols have been developed. They include among others the UK's PAS1192-2 (BSI, 2013), a specification for information management for the capital/delivery phase that represents both a 'level of model detail' for graphic content and 'level of model information' for non-graphic content. Similarly, Canada's most recent AEC (CAN) (2014) protocol and the USA's BIMForum's LOD specification (2015) both define progressive model development methodologies for element geometry and associated attribute information.

Figure 16 Synthesis of formats and documents through the building 'BOL' (see online version for colours)

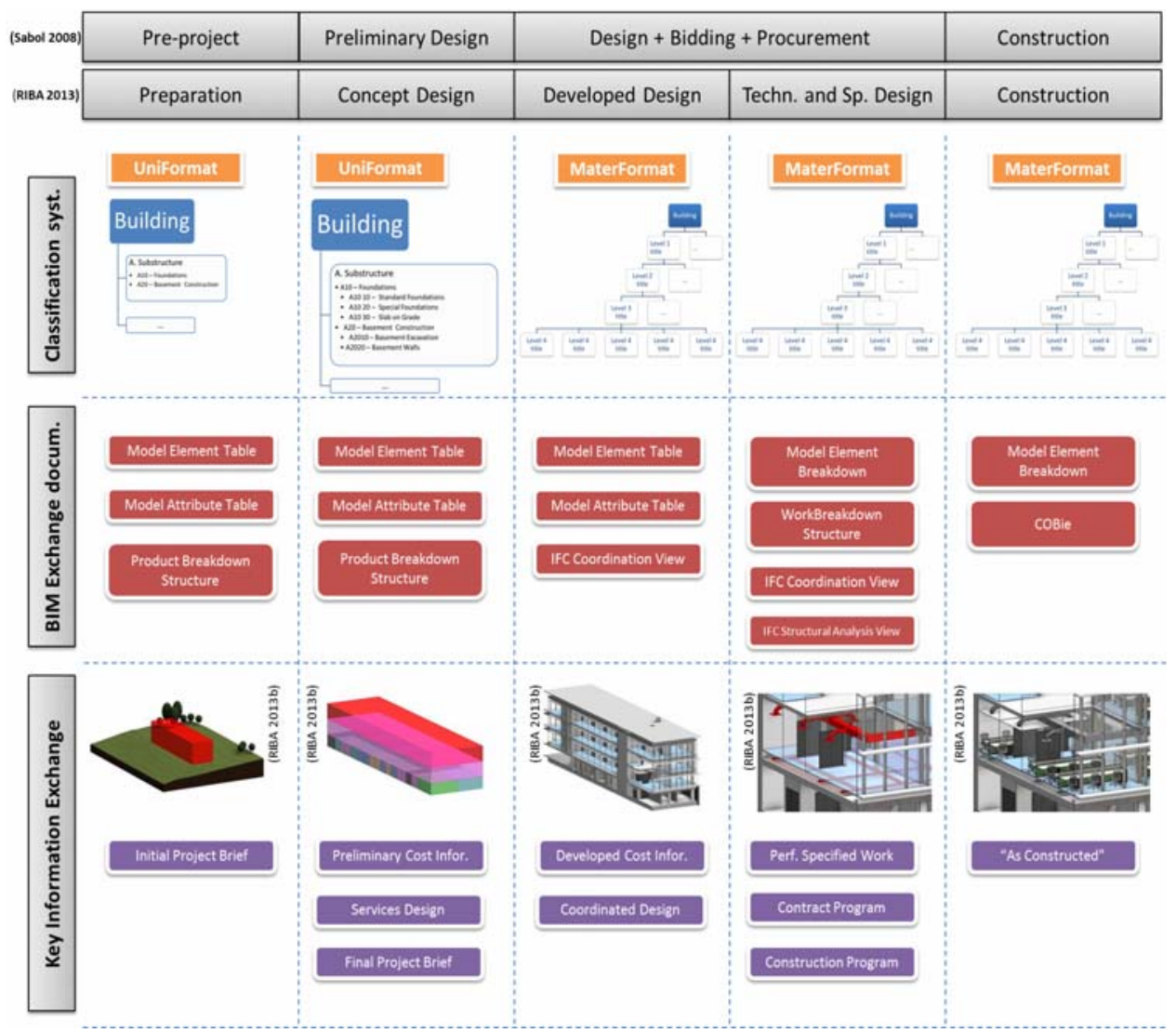

In the design stage, the IFC coordination view (the current version is IFC coordination view 2.0) is used for discipline models coordination purpose, while IFC structural analysis view makes it possible to share structural elements information for structural modelling and analysis. In the bidding and construction phases, the MEB (or PBS) and the WBS are used for planning (4D simulation) and cost estimation (5D simulation). COBie is used at the construction phase in order to collect information for facility management.

The key information exchanged at the completion of the preparation stage is the initial project brief (RIBA, 2013). The brief can be defined as the base document for the 
design and shows "the background and requirements for a building project" (Ryd, 2004). It is also known as the program in some countries, e.g., in Sweden (Ryd, 2004). A final project brief is developed at the end of the concept design. It can include in addition to the project background and its desired outcomes, cost and time targets, the procurement instructions, the site conditions and other factors that may influence design and construction (Othman et al., 2004). According to the RIBA plan of work, the development of the brief can be decomposed into three phases: the client needs definition, the strategic brief development as a starting point for the design process (after the feasibility studies) and the project brief development (frozen when the detailed proposal is completed) (Othman et al., 2004).

The key information exchanges are the developed cost information and the coordinated design at the end of the developed design phase (RIBA, 2013). At the end of the technical and specialist design phases, the key information exchanges focus on the performance specified work, the contract program and the construction program.

\section{Discussions}

The first lesson of this study suggests that the BOL steps in the construction and shipbuilding industries are quite similar, although different names are used to designate more or less comparable phases (Figure 1, Figure 2 and Table 1). The two products are first designed (through different design steps) on the basis of the customer's specifications, before being built (in the case of a building) or manufactured (in the case of a ship). The product (building or ship) is composed of different components, justifying the use of a product breakdown system (or structure) for different usages in the two industries (Figure 7 and Figure 14). Interestingly, the content of Figure 7 is closer to a PBS from construction industry than to a WBS, which is more activity oriented.

While the BOM and PS are two well-known and used concepts in the shipbuilding industry, similar concepts appear in the construction industry using different names. As shown in Figure 6 and Figure 8, the evolution of the BOM throughout the ship's BOL includes its different views, its source and its relationship to the PS and the 3D model. Similar observations are made in discrete manufacturing outside the shipbuilding industry (Figure 4 and Figure 5). While MET, MEB and PBS are similar to BOM, they also support distinct purposes. The BOM basically provides an organised list of components, with their quantities, that compose the product. The PBS is a hierarchical decomposition of the building as a product; in practice the PBS associates a code (e.g., UniFormat) to each component. As an organised list of components, the PBS is close to a BOM. The MET exploits the PBS so as to plan the upcoming modelling task by adding, for each component, which is responsible for what and at what LOD. The MEB reflects the PBS and the MET, but associates a 3D model to each component of the building. In that sense, the MEB is similar to the BOM, such as seen by comparing Figure 3 and Figure 14.

In the construction industry, several product classification systems exist. The low level of detail of the UniFormat classification system compared to that of the MasterFormat system echoes the lower level of detail of the SWBS (used for the MML) compared to the P\&ID system plan (used for the planning BOM) (Figure 6 and Figure 8). 
Table 1 Main comparison elements between BIM in construction and PLM in shipbuilding

\begin{tabular}{|c|c|c|}
\hline Parameters & PLM in shipbuilding & BIM in construction \\
\hline The product & $\begin{array}{l}\text { The ship is composed of different } \\
\text { components }\end{array}$ & $\begin{array}{l}\text { The building is composed of different } \\
\text { components }\end{array}$ \\
\hline \multirow{3}{*}{$\begin{array}{l}\text { The main phases } \\
\text { of the product } \\
\text { BOL }\end{array}$} & - Design & - Design \\
\hline & - Erection & - Construction \\
\hline & - Commissioning & - Commissioning \\
\hline \multirow{4}{*}{$\begin{array}{l}\text { Data structure } \\
\text { documents used } \\
\text { in PLM or BIM } \\
\text { projects }\end{array}$} & - BOM, bill of materials & - PBS, product breakdown structure \\
\hline & - PS, product structure & - MET, model element table \\
\hline & - WBS, work breakdown & - MEB, model element breakdown \\
\hline & structure & - WBS, work breakdown structure \\
\hline \multirow{4}{*}{$\begin{array}{l}\text { Existing } \\
\text { hierarchical and } \\
\text { enumerative } \\
\text { classification } \\
\text { systems }\end{array}$} & \multirow{4}{*}{$\begin{array}{l}\text { No standardised classification } \\
\text { structure identified }\end{array}$} & MasterFormat \\
\hline & & UniFormat \\
\hline & & Omniclass \\
\hline & & (Others according to the countries) \\
\hline \multirow[t]{6}{*}{$\begin{array}{l}\text { Need for } \\
\text { different views }\end{array}$} & $\begin{array}{l}\text { Different views used for different } \\
\text { needs, e.g.: }\end{array}$ & $\begin{array}{l}\text { IFC-based model view definitions, } \\
\text { e.g.: }\end{array}$ \\
\hline & \multirow{4}{*}{$\begin{array}{l}\text { - SWBS, system work breakdown } \\
\text { structure (used for main } \\
\text { machinery list) } \\
\text { - P\&ID, piping and instrumental } \\
\text { diagram system plan (used for } \\
\text { the planning bill of materials) }\end{array}$} & $\begin{array}{l}\text { - IFC } 2 \times 3 \text { coordination view (used for } \\
\text { disciplines models coordination) }\end{array}$ \\
\hline & & \multirow{4}{*}{$\begin{array}{l}\text { - IFC } 2 \times 3 \text { structural analysis view } \\
\text { (used to share structural elements } \\
\text { information) } \\
\text { - IFC } 2 \times 3 \text { basic FM handover view } \\
\text { (used for facility management } \\
\text { handover) }\end{array}$} \\
\hline & & \\
\hline & & \\
\hline & $\begin{array}{l}\text { - Non-isomorphic hierarchies' } \\
\text { model }\end{array}$ & \\
\hline
\end{tabular}

To summarise, in BIM, 'classification' is a means to describe construction entities in a standardised way (Afsari and Eastman, 2016). A classification system sorts a series of objects into different classes regrouping members with specific properties (Ekholm, 1996). "By giving the proper classification code to product models, they can be arranged for construction information or cost estimation within the building model and also they can be sorted within product databases" (Afsari and Eastman, 2016). In PLM, there is no such standardisation, while the term 'classification' is used to designate the system functionalities that help organise some data through attributes or meta-data, in order to easily retrieve similar data, such as standard parts for example (CIMData, 2017).

The notion of MVD in the BIM approach can be compared to the notion of view for the BOM under the PLM approach. For example, the IFC $2 \times 3$ coordination view, the IFC $2 \times 3$ structural analysis view and the IFC $2 \times 3$ basic FM handover view evoke the idea of different IFC views corresponding to different needs, similar to the different views of a PS (Figure 4). However, in the construction industry, our study does not find explicit relationships on the one hand among these documents and on the other hand between these documents across the key information exchanges (see Figure 16). Indeed, by 
analysing both the BIM implementation guides and the scientific literature, it appears that there is no research that has investigated this type of relationship.

It should also be highlighted that the fact that different words are used to describe similar concepts used in both industries makes it difficult for the specialist from one of the two industries to easily familiarise themselves with the other industry. This makes it difficult to transfer knowledge and good practice from one industry to another and demonstrates the need to build bridges between the two communities.

\section{Conclusions}

The work presented in this article is one of the first steps in a larger research effort to compare the construction industry with other comparable discrete manufacturing industries. It is a question of creating a bridge between universes that are somewhat comparable in terms of their conceptual underpinnings but do not use the same terminology, ontologies or taxonomies yet would benefit from sharing best practices. The aim is therefore to make possible cross-pollination between the technological approaches of the two worlds, so as to exchange and benefit from knowledge transfer between the two industries. At the present stage of research, it appears that the shipbuilding and construction industries share a number of similar characteristics. In addition, several documents and views used in the two industries are similar. But while in shipbuilding the links between the PS, the BOM and the product model appear quite clearly defined in the dedicated PLM literature, it seems that the question of the links between the corresponding concepts has been less developed in the BIM approach in construction.

Future works will deepen the comparison between how PLM and BIM tools allow PS manipulation. The current discussion about PS and its evolution through a project would naturally lead to studying the concepts and tools used to manipulate workflows and their automation, so as to compare them between shipbuilding and construction in future work. The aim is to provide a factual and precise comparative approach which could eventually, according to the findings, lead to a cross pollination from the PLM approach to the BIM approach. Moreover, it will be important to study how the IFC information model can efficiently be placed again at the heart of BIM practices in order to provide the critical structuring backbone role, to make it possible to implement an information-centred construction project management.

\section{References}

AEC (CAN) (2014) BIM Protocol - Implementing Canadian BIM Standards for the Architectural, Engineering and Construction Industry Based on International Collaboration, Version 2, CanBIM, Toronto, September.

AEC Magazine (2014) The Problem with COBie, AEC Magazine [online] http://aecmag.com/ technology-mainmenu-35/598-the-problem-with-cobie (Accessed July 2017).

Afsari, K. and Eastman, C.M. (2016) 'A comparison of construction classification systems used for classifying building product models', 52nd ASC Annual International Conference Proceedings, pp.1-8.

AIA (2008) E202-2008 Building Information Modeling Protocol Exhibit, American Institute of Architects, Washington, DC. 
Aram, S. and Eastman, C. (2013) 'Integration of PLM solutions and BIM systems for the AEC industry', Proceedings of 30th International Symposium of Automation and Robotics in Construction and Mining, Montreal, pp.1046-1055.

Arayici, Y., Coates, P., Koskela, L., Kagioglou, M., Usher, C. and O’Reilly, K. (2011) ‘Technology adoption in the BIM implementation for lean architectural practice', Automation in Construction, Vol. 20, No. 2, pp.189-195, Elsevier B.V.

Baccarini, D. (1996) 'The concept of project complexity - a review', International Journal of Project Management, Vol. 14, No. 4, pp.201-204.

BIMForum (2015) Level of Development Specification. For Building Information Model, Version 2015.

Bolpagni, M. and Ciribini, A.L.C. (2016) 'The information modeling and the progression of data-driven projects', in CIB World Building Congress, pp.296-307.

Boton, C. (2013) Conception de Vues Métiers Dans Les Collecticiels Orientés Service: Vers Des Multi-Vues Adaptées Pour La Simulation Collaborative 4D/nD de La Construction, Thèse de doctorat, Université de Lorraine.

Boton, C., Rivest, L., Forgues, D. and Jupp, J. (2016) 'Comparing PLM and BIM from the product structure standpoint', in Harik, R., Rivest, L., Bernard, A., Eynard, B. and Bouras, A. (Eds.): Product Lifecycle Management for Digital Transformation of Industries. PLM 2016. IFIP Advances in Information and Communication Technology, Vol. 492, pp.443-453, Springer, Columbia, USA.

Brière-Côté, A., Rivest, L. and Desrochers, A. (2010) 'Adaptive generic product structure modelling for design reuse in engineer-to-order products', Computers in Industry, Vol. 61, No. 1, pp.53-65.

Brodt, W. (2016) Omniclass Whole Building Design Guide Resource, WBDG [online] http://www. wbdg.org/resources/omniclass.php (accessed February 2018).

BSI (2013) PAS 1192-2:2013 Specification for Information Management for the Capital/delivery Phase of Construction Projects Using Building Information Modelling, The British Standards Institution.

BSI (2014) BSI Standards Publication Collaborative Production of Information Part 4: Fulfilling Employer's Information Exchange Requirements Using COBie - Code of Practice, The British Standards Institution.

Chelson, D.E. (2010) The Effects of Building Information Modeling on Construction Site Productivity, Doctoral thesis, Faculty of the Graduate School, University of Maryland.

CIMData (2017) PLM Glossary: Terms \& Acronyms [online] https://www.cimdata.com/images/ Downloads/CIMdata_PLM_Glossary.pdf (accessed 6 February 2018).

Eadie, R., Browne, M., Odeyinka, H., McKeown, C. and McNiff, S. (2013) 'BIM implementation throughout the UK construction project lifecycle: an analysis', Automation in Construction, December, Vol. 36, pp.145-151, Elsevier B.V.

East, E.W. and Brodt, W. (2007) 'BIM for construction handover', Journal of Building Information Modeling, Fall, pp.28-35.

East, E.W., Nisbet, N. and Liebich, T. (2013) 'Facility management handover model view', Journal of Computing in Civil Engineering, Vol. 27, No. 1, pp.61-67.

Eastman, C., Teicholz, P., Sacks, R. and Liston, K. (2008) BIM Handbook: A Guide to Building Information Modeling for Owners, Managers, Designers, Engineers, and Contractors, 2nd ed., Wiley, Hoboken, New-Jersey.

Eastman, C.M., Jeong, Y-S., Sacks, R. and Kaner, I. (2010) 'Exchange model and exchange object concepts for implementation of national BIM standards', Journal of Computing in Civil Engineering, Vol. 24, No. 1, pp.25-34.

Egan, J. (1998) Rethinking Construction. The Report of the Construction Task Force, Construction Task Force, $37 \mathrm{pp}$. 
Ekholm, A. (1996) 'A conceptual framework for classification of construction works', ITcon (Electronic Journal of Information Technology in Construction), Vol. 1, No. 2, pp.1-25.

Essamlali, M.T.E., Sekhari, A. and Bouras, A. (2015) 'PLM system support for collaborative development of wearable meta-products using SBCE', in Bouras, A., Eynard, B., Foufou, S. and Thoben, K.D. (Eds.): PLM 2015, IFIP AICT 467, Vol. 467, pp.33-42, Springer International Publishing Switzerland.

Eynard, B., Gallet, T., Nowak, P. and Roucoules, L. (2004) 'UML based specifications of PDM product structure and workflow', Computers in Industry, Vol. 55, No. 3, pp.301-316.

Gelder, J. (2013) OmniClassTM: A Critique, National Building Specification, NBS [online] http://www.thenbs.com/topics/PracticeManagement/articles/OmniClassCritique.asp (accessed February 2018).

Gijezen, S., Hartmann, T., Veenvliet, K.T., Hendriks, H. and Buursema, N. (2010) Organizing 3D Building Information Models With the Help of Work Breakdown Structures To Improve the Clash Detection Process, Final Report, University of Twente, 30pp.

Holzer, D. (2014) 'Fostering the link from PLM to ERP via BIM the AEC industry in transition', in Fukuda, S., Bernard, A., Gurumoorthy, B. and Bouras, A. (Eds.): PLM 2014, IFIP AICT 442, Vol. 442, pp.75-82.

Homayouni, H., Neff, G. and Dossick, C.S. (2010) 'Theoretical categories of successful collaboration and BIM implementation within the AEC industry', Construction Research Congress 2010, pp.778-788.

Howard, H., Levitt, R., Paulson, B.C., Pohl, J.G. and Tatum, C.B. (1989) 'Computer integration: reducing fragmentation in AEC industry', Journal of Computing in Civil Engineering, Vol. 3, No. 1, pp.18-32.

Jansen-Vullers, M.H., van Dorp, C.A. and Beulens, A.J.M. (2003) 'Managing traceability information in manufacture', International Journal of Information Management, Vol. 23, No. 5, pp.395-413.

Jupp, J.R. (2013) 'Incomplete BIM implementation: exploring challenges and the role of product lifecycle management functions', in Bernard, A., Rivest, L. and Dutta, D. (Eds.): Product Lifecycle Management for Society, PLM 2013, IFIP AICT 409, pp.630-640, Springer, Nantes, France.

Jupp, J.R. (2016) 'Cross industry learning: a comparative study of product lifecycle management and building information modelling', International Journal of Product Lifecycle Management, Vol. 9, No. 3, pp.258-284.

Jupp, J.R. and Nepal, M. (2014) 'BIM and PLM: comparing and learning from changes to professional practice across sectors', in Fukuda, S., Bernard, A., Gurumoorthy, B. and Bouras, A. (Eds.): PLM 2014, IFIP AICT 442, pp.41-50.

Kim, H., Lee, J., Park, J., Park, B. and Jang, D. (2002) 'Applying digital manufacturing technology to ship production and the maritime environment', Integrated Manufacturing Systems, Vol. 13, No. 5, pp.295-305.

Kreider, R. and Messner, J. (2013) 'The uses of BIM: classifying and selecting BIM uses, version 0.9', Computer Integrated Construction, p.23, University Park, PA, USA.

Kreider, R., Messner, J. and Dubler, C. (2010) 'Determining the frequency and impact of applying BIM for different purposes on building projects', Proc., 6th Int. Conf. on Innovation in Architecture, Engineering and Construction (AEC), pp.1-10.

Lebègue, E., De Almeida, R. and Pinon, L. (2014) 'Lascom AEC BIM edition, un couplage BIM IFC et PLM', BIM \& Maquette Numérique Pour L'architecture et La Construction, CSTB ed., pp.107-114, Eyrolles, Paris, France.

Lee, J.H., Kim, S.H. and Lee, K. (2012) 'Integration of evolutional BOMs for design of ship outfitting equipment', Computer Aided Design, Vol. 44, No. 3, pp.253-273, Elsevier Ltd.

Maull, R., Hughes, D. and Bennett, J. (1992) 'The role of the bill-of-materials as a CAD/CAPM interface and the key importance of engineering change control', Computing \& Control Engineering Journal, Vol. 3, No. 2, pp.63-70. 
Maurino, M. (1995) La Gestion des données techniques: Technologie du Concurrent engineering, Masson, Paris.

Othman, A.A.E., Hassan, T.M. and Pasquire, C.L. (2004) 'Drivers for dynamic brief development in construction', Engineering, Construction and Architectural Management, Vol. 11, No. 4, pp.248-258, Emerald Group Publishing Limited.

Parhiala, K., Yalcinkaya, M. and Singh, V. (2014) 'Maintenance of facilities and aircrafts: a comparison of IT-driven solutions', PLM 2014: Product Lifecycle Management for a Global Market, pp.11-20, Springer, Tokyo, Japan.

Pärn, E.A., Edwards, D.J. and Sing, M.C.P. (2017) 'The building information modelling trajectory in facilities management: a review', Automation in Construction, March, Vol. 75, pp.45-55, Elsevier B.V.

Pinquié, R., Rivest, L., Segonds, F. and Véron, P. (2015) 'An illustrated glossary of ambiguous PLM terms used in discrete manufacturing', International Journal of Product Lifecycle Management, Vol. 8, No. 2, pp.142-171.

Project Haystack (no date) [online] http://project-haystack.org/ (accessed 5 March 2018).

Ran, L. and Singh, V. (2016) 'Building information modelling-enabled best practices in AEC and takeaways for Finnish shipbuilding industry', International Journal of Product Lifecycle Management, Vol. 9, No. 3, pp.238-257.

Reefman, R.J.B. and van Nederveen, S. (2011) 'A controlled integral product model (IPM®) in building and construction', CIB W78-W102 2011: Int'l Conference.

RIBA (2013a) RIBA Plan of Work 2013 [online] https://www.ribaplanofwork.com/PlanOfWork. aspx (accessed 18 February 2017).

RIBA (2013b) RIBA Plan of Work 2013: Consultation Document, pp.1-27 [online] http://mono. eik.bme.hu/ zrostas/assets/files/CPM_PlanofWork_RIBA2013brief.pdf (accessed 18 February 2017).

Rumbaugh, J., Blaha, M., Premerlani, W., Eddy, F. and Lorenzen, W. (1991) Object-Oriented Modeling and Design, 450 pp, Prentice Hall, New York.

Ryd, N. (2004) 'The design brief as carrier of client information during the construction process', Design Studies, Vol. 25, No. 3, pp.231-249.

Saaksvuori, A. and Immonen, A. (2008) Product Lifecycle Management, 254 pp., Springer-Verlag Berlin, Heidelberg, Berlin.

Sabol, L. (2008) 'Challenges in cost estimating with building information modeling', IFMA World Workplace, pp.1-16.

Sacks, R. and Barak, R. (2008) 'Impact of three-dimensional parametric modeling of buildings on productivity in structural engineering practice', Automation in Construction, Vol. 17, No. 4, pp.439-449.

Saluja, C. (2009) A Process Mapping Procedure for Planning Building Information Modeling (BIM): Execution on a Building Construction Project, 152 pp., Department of Architectural Engineering, The Pennsylvania State University.

Schuh, G., Rozenfeld, H., Assmus, D. and Zancul, E. (2008) 'Process oriented framework to support PLM implementation', Computers in Industry, Vol. 59, Nos. 2-3, pp.210-218.

Shafiq, M.T., Matthews, J. and Lockley, S.R. (2013) 'A study of BIM collaboration requirements and available features in existing model collaboration systems', Journal of Information Technology in Construction, Vol. 18, No. 8, pp.148-161.

Sharma, R. and Kim, T. (2010) 'Development of a logic-based product life-cycle management (LBPLM) system for shipbuilding industry conceptual development', Journal of Ship Production and Design, Vol. 26, No. 4, pp.231-251.

Sharma, R., Kim, T.W., Storch, R.L., Hopman, H. and Erikstad, S.O. (2012) 'Challenges in computer applications for ship and floating structure design and analysis', CAD Computer Aided Design, Vol. 44, No. 3, pp.166-185. 
Smith, D.K. and Tardif, M. (2009) Building Information Modeling: A Strategic Implementation Guide for Architects, Engineers, Constructors, and Real Estate Managers, John Wiley \& Sons, New Jersey.

Stark, J. (2016) Product Data. In: Product Lifecycle Management, Vol. 2, Decision Engineering. Springer, Cham.

Succar, B. (2009) 'Building information modelling framework: a research and delivery foundation for industry stakeholders', Automation in Construction, Vol. 18, No. 3, 357-375, Elsevier B.V.

Succar, B., Saleeb, N. and Sher, W. (2016) 'Model uses: foundations for a modular requirements clarification language', Australasian Universities Building Education (AUBEA2016), Cairns, Australia, 6-8 July 2016.

Sunke, N. (2009) Planning of Construction Projects: A Managerial Approach, PhD thesis, Civil Engineering Department, University of Siegen, $241 \mathrm{pp}$.

Svensson, D. and Malmqvist, J. (2002) 'Strategies for product structure management at manufacturing firms', Journal of Computing and Information Science in Engineering, March, Vol. 2, pp.50-58.

Terzi, S., Bouras, A., Dutta, D., Garetti, M. and Kiritsis, D. (2010) 'Product lifecycle management - from its history to its new role', International Journal of Product Lifecycle Management, Vol. 4, No. 4, pp.360-389.

The Computer Integrated Construction Research Group (2011) BIM Project Execution Planning Guide - Version 2.1, Pennsylvania State University, University Park, USA.

Trappey, A.J.C., Peng, T-K. and Lin, H-D. (1996) 'An object-oriented bill of materials system for dynamic product management', Journal of Intelligent Manufacturing, Vol. 7, No. 5, pp.365-371.

Van Den Hamer, P. and Lepoeter, K. (1996) 'Managing design data: the five dimensions of CAD frameworks, configuration management, and product data management', Proceedings of the IEEE, Vol. 84, No. 1, pp.42-56.

Zhou, W., Heesom, D., Georgakis, P., Nwagboso, C. and Feng, A. (2009) 'An interactive approach to collaborative 4D construction planning', Electronic Journal of Information Technology in Construction, Vol. 14, No. 5, pp.30-47.

\section{Notes}

1 Computer aided facility management.

2 Computerised maintenance management system.

3 Construction operations building information exchange. 